\title{
Origin of continental crust by water- fluxed melting of thick Archean oceanic arcs
}

RONGFENG GE ${ }^{1}$, SIMON WILDE ${ }^{2}$ AND WENBIN ZHU ${ }^{1}$

${ }^{1}$ Nanjing University

${ }^{2}$ Curtin University

Presenting Author: gerongfeng@gmail.com

Among terrestrial planets and the moon in our solar system, Earth is unique and habitable in having liquid water, plate tectonics and continental crust. Yet, the role of water and, particularly, plate tectonics in the origin of continental crust remains highly controversial. Earth's early continental crust is dominated by sodic granitoids of tonalite - trondhjemite granodiorite (TTG) composition, distinct from high-K calcalkaline granitoids in younger crustal domains. Hence, the formation and secular evolution of TTGs is key to our understanding on the origin of continental crust and geodynamic regimes in the early Earth. It is generally accepted that TTGs are generated by dehydration melting of hydrated mafic rocks at high pressures $(\geq 8 \mathrm{kbar})$ and high temperatures $\left(>850^{\circ} \mathrm{C}\right)$, but their source compositions, formation conditions and tectonic settings remain debated. Recently we have documented a suite of Eoarchean $(\sim 3.7 \mathrm{Ga})$ and Mesoarchean $(3.2-3.0 \mathrm{Ga})$ TTGs from the southern Tarim Craton, northwestern China. In-situ zircon Hf and whole-rock $\mathrm{Sr}-\mathrm{Nd}-\mathrm{Hf}-\mathrm{Pb}$ isotopes demonstrate that the TTGs represent juvenile crust. Zircon trace element thermo-oxygenbarometers indicate that the TTG magmas crystallized at relatively low-temperature and oxidized conditions. Thermodynamic - geochemical modelling indicates that the parental magmas of the Eoarchean and Mesoarchean TTGs could have been produced by partial melting of moderately enriched Archean arc-like basalts at $18-20$ and $10-12$ kbar, respectively. Compared to dehydration melting, water-fluxed melting provides a more efficient way to produce voluminous TTGs and better explains the low-temperature, oxidized crystallization conditions, as well as the high $\mathrm{Nb} / \mathrm{Ta}$ ratios, of the studied TTGs. We propose that the high-pressure and low- to medium-pressure TTGs could have been produced, respectively, by water-fluxed melting of subducted and overlying protooceanic arcs built on thick Archean oceanic crust during intermittent subduction and arc accretion. Our model reinforces that the origin of Archean continental crust is intrinsically linked to an early hydrosphere and subduction - accretion tectonics. Our model also implies that the secular evolution of Archean TTGs to high-K calc-alkaline granitoids results from thinning of oceanic crust and thus oceanic arcs due to secular cooling of the mantle. 